\title{
System Matching Design And Control Optimization Of Extended- Range Electric Vehicle
}

\author{
Wang Hongyu, Zhang Chun, Liu Huandong, Xi Fuqiang, Zhao Yue \\ Weichai Power Co., Ltd, Weifang, 261000, China. \\ wanghongy@weichai.com.
}

Keywords: Component Matching; Range Extender; Control Strategy; Electric Range-Extention Vehicle(E-REV)

\begin{abstract}
By using a light bus prototype, this article discusses system design with vehicle dynamic demand, driving environment, cost and etc., proposes a self-adapt control method to adjust start and stop time of the range extender based on the vehicle's average output power demand and battery SOC status. The range extender works in the most efficient point (area) with constant power consumption after system cranks. Finally, field tests are done according to an actual bus routine and $\mathrm{CCBC}$ situation. These results verify the rationality of system architecture and corresponding control method which effectively improve the overall fuel economy.
\end{abstract}

\section{Introduction}

About studies on system design and control logic of extended range electric vehicles, reference [1] indicates regular energy control method to set optimal operation points of engine. Reference [2] uses energy management method of fixed points which uses battery power for short distance driving and range extender power for long distance when power battery SOC reached low threshold. Tongji University's patent reference [3] is based on energy control method of optimal power curve, which collects real-time information and data according to demanded power and selfadjusts the arrangement of energy. Reference [4] corrects the generated power, SOC status, power variation rate and realtime measurement of the vehicle power then sets the operation speed and torque of range extender based on system's oil - electricity conversion efficiency curve. Reference [5] uses dynamic planning method to search for best path and energy consumption strategy by analyzing known (or partially known) driving circle. Further studies include artificial intelligent control methods like fuzzy logic, BP neural network etc. have been applied for E-REV in the real world.

By reasonably selecting parameters of system components and simplifying effective control method, the system can then be used for practical application to reduce the fuel economy and emissions. Based on engineering practice, this article discusses system design with the prototype of a light bus, and comes up with a self-adaptation control method by adjusting start and stop time of the range extender according to the vehicle accurate output power and battery SOC status. After system is launched, the ranger extender works with constant output power with efficient area in the engine and generator torque-speed curve to achieve high efficiency and stability. Finally, the rationality of control algorithm is verified through vehicle tests that the self-adaptation control method is capable of improving the fuel economy, and preventing a continuous drop of electricity which could damage the battery life.

\section{Component Matching Design}

The system match of E-REV shall consider the vehicle dynamic demands including maximum speed, maximum grad ability, acceleration, cost and other vehicle running conditions (including temperature, altitude, wind speed, etc.), as while as transmission efficiency and so on. This article discusses the design method of a light bus E-REV system, the vehicle technical parameters are shown in Table 1, the EREV performance indicators are shown in Table 2.

\begin{tabular}{|c|c|}
\hline Technical Parameters & Value \\
\hline No - load mass $\left(m_{0} / \mathrm{kg}\right)$ & 2950 \\
\hline Total mass $\left(m_{1} / \mathrm{kg}\right)$ & 4800 \\
\hline Tire rolling radius $(r / \mathrm{m})$ & 0.364 \\
\hline Dimensions $(/ \mathrm{mm})$ & $6100 * 1993 * 2530$ \\
\hline Windward area $\left(\mathrm{A} / \mathrm{m}^{2}\right)$ & 4.2 \\
\hline Drag coefficient $\mathrm{C}_{\mathrm{D}}$ & 0.7 \\
\hline Rolling resistance coefficient $f$ & 0.014 \\
\hline Transmission efficiency $\eta$ & 0.9 \\
\hline Main reduction ratio $i$ & 4.875 \\
\hline
\end{tabular}

Table1: Vehicle Technical Parameter 


\begin{tabular}{|c|c|}
\hline Design Indicators & Value \\
\hline Highest speed $\left(v_{f} / \mathrm{km}^{*} \mathrm{~h}^{-1}\right)$ & $\geq 70$ \\
\hline $\begin{array}{c}\text { Maximum climbing degree at } \\
20 \mathrm{~km} / \mathrm{h}\left(\alpha_{\max } / \%\right)\end{array}$ & $\geq 20$ \\
\hline $\begin{array}{c}0-50 \mathrm{~km} / \mathrm{h} \text { acceleration time at } \\
40 \mathrm{~km} / \mathrm{h}\left(S_{E V} / \mathrm{km}\right)\end{array}$ & $\leq 20$ \\
\hline $\begin{array}{c}\text { Pure electric life mileage at } 40 \mathrm{~km} / \mathrm{h} \\
\left(S_{E V} / \mathrm{km}\right)\end{array}$ & $\geq 50$ \\
\hline Total mileage $(S / \mathrm{km})$ & $\geq 300$ \\
\hline
\end{tabular}

Table2: E-REV Performance Design Indicators

\subsection{Motor Matching Design}

As the only power source of E-REV, the traction motor needs careful consideration since its parameters could directly influence the dynamic performance of overall vehicle. The formula for calculating the parameters of motor can be found in the published literatures ${ }^{[8,9]}$. The peak power and peak torque of the motor are obtained according to the driving equation of vehicle dynamics, the driving resistance balance equation and the relationship between the torque and power.

Calculating motor peak power according to the maximum vehicle speed requirement:

$$
P_{\max 1}=\frac{v_{f}}{3600 \eta}\left(m g f+\frac{C_{D} \cdot A \cdot v_{f}^{2}}{21.15 m g}\right)
$$

Calculating motor peak power according to the maximum climbing requirements:

$$
P_{\max 2}=\frac{m g v_{P}}{3600 \eta}\left(f \cos \alpha_{\text {max }}+\sin \alpha_{\text {max }}+\frac{C_{D} \cdot A \cdot v_{\max }^{2}}{21.15 m g}\right)
$$

Calculating motor peak power according to the maximum acceleration requirement:

$$
P_{\max 3}=\frac{1}{1000 \eta}\left(\frac{\delta m}{2 t_{a}}\left(v_{f}^{2}+v_{b}^{2}\right)+\frac{2}{3} m g f v_{f}+\frac{\rho_{a} C_{D} \cdot A v_{f}^{3}}{5}\right)
$$

The motor peak power is $P_{\max }=\max \left(P_{\max 1}, P_{\max 2}, P_{\max 3}\right)$. According to the relationship between peak (nominal) torque and peak (rated) power of permanent magnet synchronous motor, the motor peak and rated torque could be calculated as follows:

$$
\begin{aligned}
T_{\max } & =\frac{9550 P_{\max }}{n_{e}} \\
T_{e} & =\frac{9550 P_{e}}{n_{e}}
\end{aligned}
$$

According to the formula, the quality of the whole vehicle is directly proportional to the power of the traction motor and reducing the mass of the whole vehicle could correspondingly reduce the power and cost of the traction motor. Therefore, selection of light-weight system components is of high priority when vehicle performances are met and safety is guaranteed. According to the power performance test for hybrid-power vehicle of Chinese National Standard ${ }^{[10]}$, and motor power ratings ${ }^{[11]}$, with overload co-efficiency of 2.5 , the drive motor's technical parameters could be calculated as follows shown in Table3:

\begin{tabular}{|c|c|}
\hline Technical Parameters & Value \\
\hline Peak power $\left(P_{\max } / \mathrm{kW}\right)$ & 60 \\
\hline Rated power $\left(P_{e} / \mathrm{kW}\right)$ & 24 \\
\hline Peak Torque $\left(\mathrm{T}_{\max } / \mathrm{Nm}\right)$ & 230 \\
\hline Rated Torque $\left(\mathrm{T}_{e} / \mathrm{Nm}\right)$ & 100 \\
\hline Highest speed $\left(n_{\max } / \mathrm{r}^{*} \min ^{-1}\right)$ & 2500 \\
\hline Rated speed $\left(n_{\max } / \mathrm{r}^{*} \min ^{-1}\right)$ & 1200 \\
\hline
\end{tabular}

Table3: Motor Technical Parameters

\subsection{Battery Matching Design}

The battery is the major energy source for E-REV. When selecting battery, the capacity must meet pure electric mileage demand, and the charging and discharging power must meet the vehicle power demand ${ }^{[12]}$.In addition, we need take the cost of the battery, the service life and efficiency, etc into consideration.

The cost and weight of the battery increase with the capacity According to the pure electric mileage $S_{E V}$ index and the maximum demand power $P_{m m}$ of motor, we can then select the power battery capacity so that the battery capacity will not be too large, while it also meets the vehicle performance demands. The specific information is shown in the following content:

$$
\begin{gathered}
P_{\text {batt_max }}=\frac{k C_{\text {batt }} U_{\text {batt }}}{1000} \geq \frac{P_{\text {mm }}}{\eta_{\text {motor }}}+P^{\prime} \\
E_{E V}=\frac{U_{\text {batt }} \cdot C_{e}}{1000}=\frac{P_{E V} \cdot S_{E V}}{\eta_{\text {motor }} \cdot \eta \cdot v_{E V}} \\
=\frac{U_{\text {batt }} \cdot S_{E V}}{3600 \eta_{\text {motor }} \cdot \eta \cdot \eta_{\text {batt }} \cdot v_{E V}}\left(m g f+\frac{U_{\text {batt }} \cdot C_{D} \cdot A \cdot v_{E V}^{2}}{21.15}\right)
\end{gathered}
$$

In the formula, driving motor efficiency $\eta_{\text {motor }}$ values 0.95 and battery discharge efficiency $\eta_{\text {batt }}$ values 0.95 . Electric auxiliary machine and other electricity accessories power $P$ is around $7 \mathrm{~kW}$. Based on the product specifications, vehicle technical parameters and specs of existing battery manufacturers, the calculated power battery capacity is $60 \mathrm{~A} \cdot \mathrm{h}$ and the maximum discharge power $\mathrm{k}$ is $3.44 \mathrm{~h}^{-1}$.

The life and efficiency of the battery are closely related to the environment temperature ${ }^{[13]}$. The relationship between the capacity retention rate and the cycle times of Lithiumion battery cell under various temperatures is shown in Figure $1^{[14]}$. The figure shows that the environment temperature being too low or too high will speed up the decay rate of the battery capacity and further affect the battery life cycle. Therefore, when selecting the battery for the vehicle, we should select the ones with insulating and heating function in the low temperature environment and the ones with cooling and radiating function in the high temperature environment. 


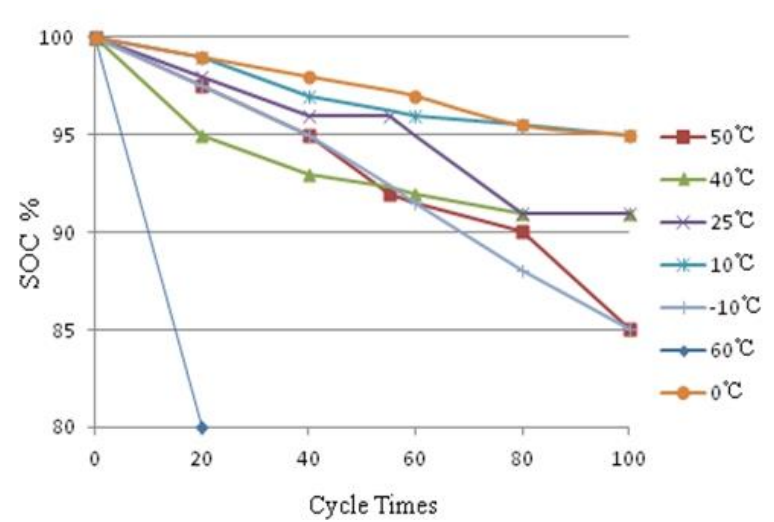

Figure 1: Lithium-ion battery cell's capacity retention rate cycle times relationship

The charge and discharge amplitude of the battery will also affect the battery consistency, thereby causing damage to the battery life. Figure 2 shows the relationship between the cycle times and the charge and discharge amplitude of several common batteries ${ }^{[15,16]}$. When the SOC changing amplitude is over $60 \%$, the cycle times are over 3000 . When the SOC changing amplitude is within $20 \%$, the cycle times will be increased 5 times and up to 15000 . Thus reducing the battery charge and discharge amplitude could extend the battery life. The range extension generator can help the battery to supply extra power for the motor, in this way, it is able to ensure the mileage of the vehicle, avoid the battery over-discharge and greatly enhance the battery life. Therefore, when selecting batteries for E-REV, we could appropriately reduce the battery discharge amplitude according to range extender.

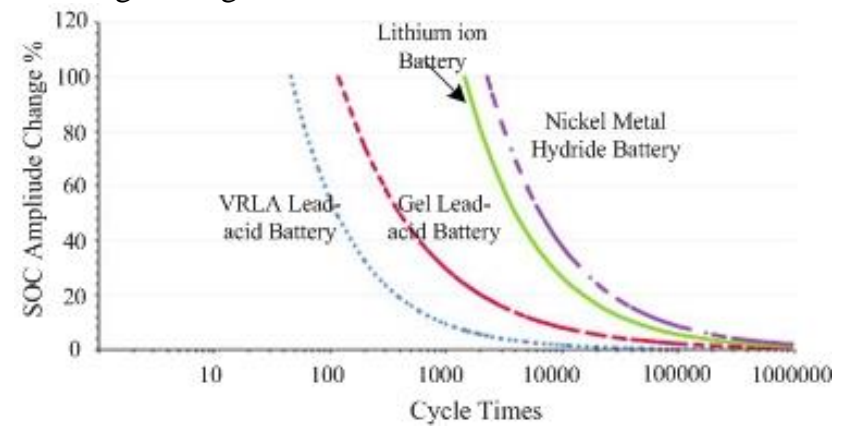

Figure 2: Several common batteries' cycle times - charge and discharge amplitude relationship

\subsection{Range Extender Matching Design}

Under normal running situation, the range extender is not directly involved in driving and it is mainly used to assist the battery to extend the mileage. When the battery is in failure mode, it is able to ensure that the vehicle can drive home at a pre-defined $v_{E V}$ speed. The control method in the paper is fixed-point energy management method meaning that the range extender works only at certain points without high power and high torque, the gasoline engine and permanent magnet synchronous motors are selected according to these and those fixed-points are generally in high-efficiency working area of the engine and the generator. According to the driving condition at constant speed, total mileage requirement and technical parameters of the vehicle, the output power of the range extender and fuel tank volume could be calculated:

$$
\begin{gathered}
P_{A P U}=\frac{v_{E V}}{3600 \eta \cdot \eta_{\text {motor }}}\left(m g f+\frac{U_{\text {batt }} \cdot C_{D} \cdot A \cdot v_{E V}^{2}}{21.15}\right)+P^{\prime} \\
V=\frac{b e \cdot P_{A P U} \cdot\left(S-S_{E V}\right)}{0.725 v_{E V}}
\end{gathered}
$$

Combined with the market's existing engine and permanent magnet synchronous motor products, we selected a range extender with fuel consumption rate of $260 \mathrm{~g} / \mathrm{kWh}$, which is calculated by engine fuel consumption rate and generator effectivense. The output power of the range extender $P_{A P U}$ is $18 \mathrm{~kW}$ and the fuel tank volume is about $40 \mathrm{~L}$. The range extender's Speed - Power relationship is shown in Figure 3, and the specific parameters is in Table 4.

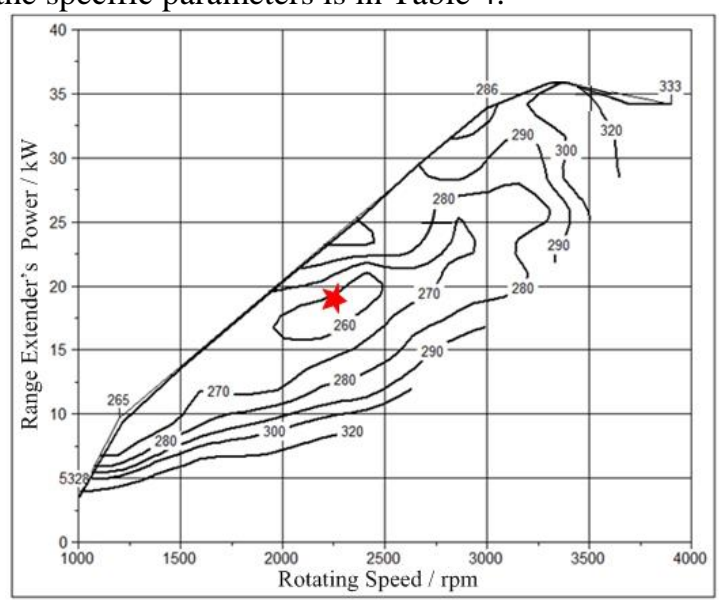

Figure 3: The range extender' s speed - Power relationship

\begin{tabular}{|c|c|}
\hline Technical Parameters & Value \\
\hline $\begin{array}{c}\text { Economic power / Rotating } \\
\text { speed(kW/rpm) }\end{array}$ & $18 / 2250$ \\
\hline Peak power / Rotating speed(kW/rpm) & $38 / 4000$ \\
\hline Engine displacement (cc) & 1193 \\
\hline
\end{tabular}

Table4: Motor Technical Parameters

\section{Control Optimization}

Operation modes of extended-range electric vehicle could be divided into pure electric mode and extended range mode. In the pure electric mode, the range extender does not work and the traction motor keeps consumption battery power to propel. When the battery power is low, the range extender starts to kick in for extending mileage, and then the system enters into the extended range mode. There are two major factors influencing E-REV's fuel economy and emission, one is when the range extender cannot work stably in the high-efficiency area and the other is when the range extender starts and stops too frequently. Therefore, in this paper, adaptive control method is used to set $\mathrm{SOC}_{0}$ as the initial value of the start time for range extension mode according to $P_{A P U}$. Compared with the average power $\bar{P}$ of the preceding time period $\Delta \mathrm{t}$ and $P_{A P U}$, the start time of the range extender is automatically adjusted, for example: 
a 、 as $\bar{P}>P_{A P U}$, the range extender's start time is $\mathrm{SOC}_{0}+\triangle \mathrm{SOC}(\triangle \mathrm{SOC}>0)$;

b、 as $\bar{P}>P_{A P U}$, the range extender's start time is $\mathrm{SOC}_{0^{-}}$ $\triangle \mathrm{SOC}(\triangle \mathrm{SOC}>0)$;

c、 as $\bar{P}=P_{A P U}$, the range extender's start time is $\mathrm{SOC}_{0}$

Then we can adjust the starting time with the vehicle actual output power. Similarly the range extender stops when both the vehicle average power $\bar{P}$ is lower than the range extender power $P_{A P U}$ and the battery SOC reaches a certain limit. After starting, the range extender works at the constant power point $P_{A P U}$ which is generally the most efficient operating point.

\section{Experimental Verification}

Prototype vehicle was then built according to the artecture design method. Self-adaptive control method is used to control the range extender to generate electricity. The dynamic performance of the vehicle was verified through a series of $0-50 \mathrm{~km} / \mathrm{h}$ acceleration tests. Under an actual city bus routine and CCBC condition, a test was carried out to make a comparative analysis of battery SOC changes and vehicle fuel consumption situation.

Figure 4 shows the results of $0-50 \mathrm{~km} / \mathrm{h}$ acceleration test of the E-REV. The vehicle speed is accelerated from 0 to $50 \mathrm{~km} / \mathrm{h}$ in $11 \mathrm{~s}$ and the maximum speed reached up to 70 $\mathrm{km} / \mathrm{h}$, satisfying the dynamic performance design requirement of the vehicle.

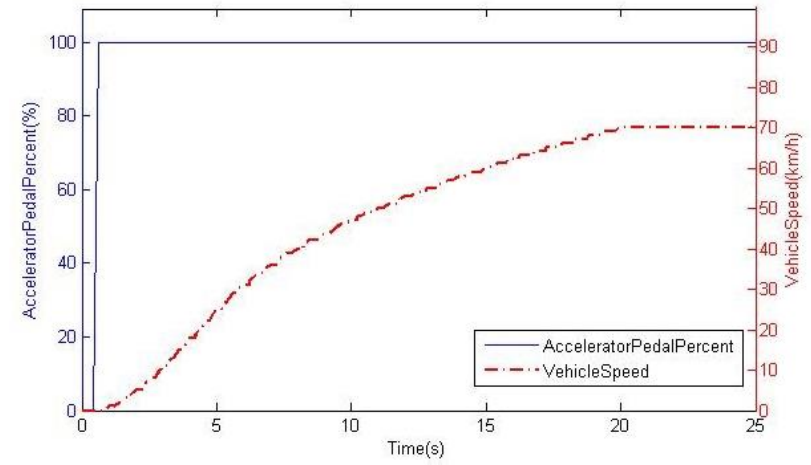

Figure 4: $0-50 \mathrm{~km} / \mathrm{h}$ acceleration test of the E-REV

Comparing Figure 5 and Figure 6, with the control method proposed in this paper, the range of variation of battery SOC is about $6 \%$ under the classic city bus cycle. After driving 28 $\mathrm{km}$ the range of variation of battery SOC is within $7 \%$ under the actual bus cycle of a city. The control method effectively controls the SOC range of variation and extends the battery life.

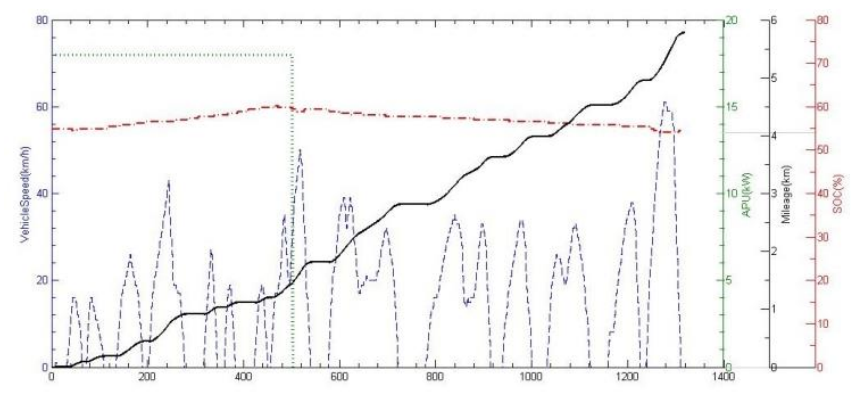

Figure 5: CCBC condition test of the E-REV

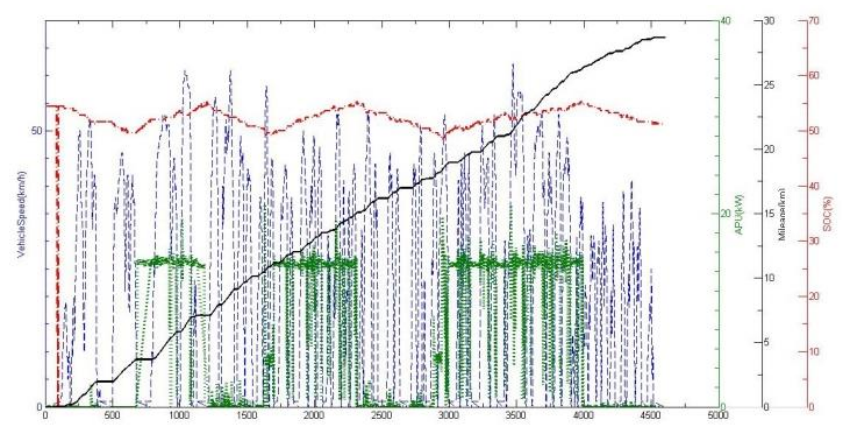

Figure 6: An actual city bus routine of the E-REV

According to the conversion relationship between electricity consumption and fuel consumption in the national standard GBT19754-2005 ${ }^{[17]}$, the following formula is used to calculate the fuel consumption of 100 kilometers under two driving conditions. The results show that the fuel consumption of $100 \mathrm{~km}$ of the extended-range electric vehicle is about $10 \mathrm{~L} / 100 \mathrm{~km}$ under $\mathrm{CCBC}$ condition and the actual city bus routine, saving fuel than the traditional car by about $36 \%$.

$$
Q=\frac{Q_{f}+\frac{Q_{E}}{f_{E}}}{s}
$$

Among them, $Q_{F}$ for fuel consumption, $Q_{E}$ for electricity consumption, $s$ for the mileage, oil and electricity conversion coefficient $f_{E}$ taking $2.5 \mathrm{kWh} / \mathrm{L}$.

\begin{tabular}{|c|c|c|}
\hline Models & $\begin{array}{c}\text { CCBC/ } \\
(\mathrm{L} / \mathbf{1 0 0 k m})\end{array}$ & $\begin{array}{c}\text { Actual Bus Path } \\
\text { of } \text { a City }(\mathbf{L} / \mathbf{1 0 0 k m})\end{array}$ \\
\hline Traditional Vehicle & $15.6 \mathrm{~L} / 100 \mathrm{~km}$ & $16 \mathrm{~L} / 100 \mathrm{~km}$ \\
\hline E-REV & $9.9 \mathrm{~L} / 100 \mathrm{~km}$ & $10.4 \mathrm{~L} / 100 \mathrm{~km}$ \\
\hline
\end{tabular}

Table5: Vehicle $100 \mathrm{~km}$ fuel consumption test of the traditional vehicle and E-REV

\section{Acknowledgements}

(1) With the prototype of a light bus, this article discussed system architecture design according to the vehicle dynamic demands, driving environment and cost. And testing results verified the rationality.

(2) This article proposed a self-adaption control method by adjusting start and stop time of the range extender according to vehicle accurate output power. The experimental results 
show that the method can effectively control the range ability and improve the fuel economy with low emission.

\section{References}

[1] NIU Ji-gao, SI Lu-lu, ZHANG Tong. Simulation Analysis of Energy Control Strategy for an Extended-Range Electric Vehicle, Journal of Shanghai Jiao Tong University[J], pp.140-145,(2014).

[2] Niu Jigao, Zhou Su. On/Off Timing Optimization for the Range-extender in Extended-Range Electric Vehicles, Automotive Engineering[J], pp.418-422,(2013).

[3] Song Ke, Jiang Wenjia, Zhang Tong; An On - line Self adjusting Energy Management Method and System for an Extended-Range Electric Vehicle.China, 103507656A [P].(2013).

[4] SHEN Yongpeng, Wang Yaonan, MENG Bumin, LI Huixian. Power Flow Optimization Strategy of Range Extender Electric Vehicle, Proceedings of the CSEE[J], pp.4035-4042, (2015).

[5] Cao Dongjiang. Mutipower System Energy Management Stratagy Research for Extended-Range Electric Bus[D]. Beijing Institute of Technology,(2014).

[6] ZHAO Jing-bo, BEI Shao-yi, FENG Jun-ping. Multimode Switching Control of Motor-Driving System of Range-Extended Electric Vehicle, Journal of Shanghai Jiao Tong University[J], pp.1726-1730,(2015).

[7] Zhao Hongyan, Dong Weijiang. Design and Control of Extended-Range Electric Vehicles, Chinese Journal of Automotive Engineering[J], pp.342-347,(2014)

[8] Zhou Su, Niu Jigao, Chen Fengxiang, Pei Fenglai, Automotive Engineering[J], pp.924-929,(2011).

[9] Yu Zhisheng. Theory of Automobiles(4th ed.)[M]. Beijing:China Machine Press, (2011).

[10] GB/T19752-2005. Dynamic Performance of Hybrid Electric Vehicles Test Procedures. [S]. Beijing:China Standard Press, (2006).

[11] GB/T18488.1-2015. Drive motor systems for electric vehicles Part one. [S]. Beijing:China Standard Press, (2016).

[12] Tian Sheng, Li Yafei, Li Shicheng. Experimental Research on Lithium-ion Power Battery for Extended Range Electric Vehicle, Automobile Technology[J], pp.42-51, (2016).

[13] Wang Da, Study on Power Distribution Design Method and Control Strategy of Extended-Range Electric Vehicles[D]. Jilin University.(2016).

[14] Jiexun Liu, Dawei Gao, Jianhua Cao. Study on the effects of temperature On $\mathrm{LiFePO}_{4}$ Battery life[C]. IEEE Vehicle Power and Propulsion Conference.pp. 14361440(2012).

[15] Scott B.Peterson, Jay Apta, J.F.Whitacre.Lithium-ion battery cell degradation resulting from realistic vehicle and vehicle-to-grid utilization[J].Journal of Power Sources, pp.2385-2392,(2010).

[16] Zhang Yao, Bai Yang, Liu Xingjiang. Simulation Analysis on Thermal Behavior for Power lithium-ion Battery, Chinese Journal of Power Sources[J], pp.461463,(2005)
[17] ROSENKRANZ K. Deep-Cycle Batteries for Plug-in Hybrid Application[C]//20th International Electric Vehicle Symposium, Plug-in Hybrid Vehicle Workshop, November 15-19, 2003, Long Beach, California. 